\title{
JURIDICIDAD: DESAFÍOS Y TENDENCIAS DEL SIGLO XXI. ENCRUCIJADA AL DERECHO INTERNACIONAL Y AL ESTADO DE DERECHO INTERNO.
}

Mario Arnello Romo ${ }^{1}$

El Derecho Internacional -el que se comprende académicamente como Derecho Internacional Público-, asumiendo los profundos cambios de la sociedad internacional ocurridos en la segunda mitad del siglo xx, experimentó en los últimos decenios una evolución muy pronunciada en muchos aspectos. Lamentablemente no en todos ellos se observa similar consistencia con la naturaleza y el fin propio del Derecho Internacional. Tal inconsistencia alcanza, en este primer decenio del siglo xxi, la magnitud de configurar una encrucijada para la juridicidad del derecho.

En efecto, este derecho nace siendo un derecho propio de los Estados, creados por los Estados -únicos sujetos originarios y plenos-, y destinado a coordinar en lo posible, jurídicamente, las relaciones internacionales de los Estados. Para tal fin el Derecho fijaba -con el consenso de los Estados- las limitaciones que aceptan en la discrecionalidad y plenitud que corresponde en el ejercicio de los derechos inherentes a su independencia e igualdad soberana. En cambio, el influjo de las nuevas tendencias doctrinarias y una innegable ideología innovadora que impulsa la creación y desarrollo de nuevas áreas en el Derecho Internacional está alterando la naturaleza y fin del Derecho Internacional y su juridicidad. Y aún, por un efecto vicioso, de clara inmadurez jurídica y política, se introduce de contrabando afectando el estado de derecho interno en muchos Estados.

1 Profesor Titular de Derecho Internacional Público de la Facultad de Derecho de la Universidad de Chile 
La primera forma de evolución fue la transformación del derecho principalmente consuetudinario a ser un derecho crecientemente convencional. Grandes tratados multilaterales, con afán de ser universales $-\mathrm{y}$, por lo mismo de lenta y difícil concreción-, recogieron el derecho creado por la costumbre; sin perjuicio, otras veces, de quedar indefinidamente detenidas por el desacuerdo de los Estados en puntos importantes, lo que añadió incertidumbre a costumbres ya establecidas.

Inició la importante expansión convencional el desarrollo del Derecho Internacional Humanitario, con los grandes convenios de Ginebra de 1949, que se suman a los tratados y convenios de La Haya a principios del siglo xx, dando lugar a la creación de un nuevo derecho vinculado a la guerra; y, más precisamente, a aminorar los efectos de la guerra sobre las personas que no son o dejaron de ser combatientes.

Diversas convenciones sucesivas van ampliando el ámbito que se pretende proteger, tanto en una guerra internacional como en una guerra civil interna en un Estado, que recibe el nombre preciso de "guerra no internacional". Al efecto, son numerosos los tratados vigentes sobre las materias comprendidas en este derecho in bello de enorme significado. Y son de particular importancia los Protocolos Adicionales I y II a los convenios de Ginebra, que los interpretan, desarrollan y completan; el I respecto a la guerra internacional y el II a las normas aplicables a una guerra interna o "no internacional".

La segunda gran evolución se ha producido tras la valoración internacional de los Derechos Humanos. Y aquí la evolución, por la dinámica de la doctrina "creacionista", y de la innegable neoideología a que da origen, se está transformando en una revolución.

Los principios relativos al respeto y a la dignidad de la persona humana, señalados en la Carta de San Francisco que da origen a la Organización de las Naciones Unidas, tienen todavía un eco de los principios del ius gentium de Vitoria, aun cuando los representantes de 50 Estados aliados en guerra allí reunidos prefiriesen recordar a los enunciados en las declaraciones de las libertades y derechos del hombre de fines del siglo XviII. 
La Declaración Universal de Derechos Humanos, aprobada y aclamada por la Asamblea General de las Naciones Unidas el 10 de diciembre de 1948, que invoca la dignidad intrínseca y los derechos iguales e inalienables de todos los miembros de la familia humana, abre un camino que en el curso de medio siglo ha creado el "Derecho Internacional de los Derechos Humanos". La naturaleza jurídica de este derecho, los verdaderos sujetos de él, las instituciones que ha creado y la subordinación que ha impuesto sobre los Estados y aun sobre el Derecho Internacional, marcan ya no una evolución sino aquella revolución indicada.

No obstante todo lo positivo de su creación y desarrollo, en su impulso actual existe un aspecto negativo. Lo negativo y peligroso para su propio fin y consolidación es la creciente tentación que se revela en la propia dinámica de su aplicación, de no respetar la juridicidad. Sin esta el derecho deja de existir.

Paralelo a esta evolución revolucionaria, apoyándose en su inicio en el Derecho Internacional Humanitario, pero buscando alterar los principios de jurisdicción penal de los Estados, de largo reconocimiento internacional, se ha desarrollado el hoy día denominado Derecho Penal Internacional. Si su origen está marcado por el estatuto del Tribunal Militar Internacional de Nuremberg, no podría extrañar que su creación positiva esté viciada, en la práctica, con las tres grandes contradicciones de su origen: primero, la negación de las reglas esenciales y básicas de la jurisdicción y del derecho penal de las naciones civilizadas (incluso las de los Estados representados en el Tribunal, exceptuada la u.R.s.s. cuyo Código criminal no las reconocía); luego, la discriminación punitiva sólo aplicable a actos criminales de los vencidos, y omitir actos similares de algunos de los vencedores; y, por último, en abierto retroceso de la Historia, erigirse el vencedor en juez sobre la vida y destino del vencido.

En el ya extenso camino recorrido, aún en la práctica internacional repetida en una decena de casos, al margen de la intencionalidad humanitaria que ha existido, sea en Tribunales ad boc o en intervenciones armadas neo-humanitarias, y de la necesidad de que hubiese 
una solución frente a una tragedia, siempre, por desgracia, afloran las contradicciones, las discriminaciones políticas, y el peso del poder alterando o aún ignorando el Derecho Internacional. El Consejo de Seguridad de Naciones Unidas no ha sido ajeno a estos actos contrarios a las atribuciones que le fija la Carta. Finalmente, el estatuto de Roma y la Corte Penal Internacional que crea y regula, es la marca final de la antijuridicidad.

Por una extraña paradoja todo el movimiento revolucionario en marcha, cuya bandera inicial de promover el respeto y defensa de los derechos inalienables de la persona humana, y a cuya tarea la Declaración Universal invoca a los Estados, se ha venido transformando en una grave alteración del orden internacional. Al afectar a la juridicidad, lleva a una crisis del derecho, de la autoridad y la legalidad democrática, y aun de la soberanía nacional de los Estados, base y fundamento de existencia del orden universal.

Este artículo sólo pretende dejar planteada una advertencia respecto al derecho; los otros dos quedarán pendientes.

Alterar los fundamentos del Derecho Internacional -un orden jurídico de Estados independientes, iguales y soberanos-, y destruir la juridicidad objetiva que debe sustentar el derecho, para abrir una caja de Pandora, incierta, subjetiva, ideologizada y discriminatoria, podrá terminar con el orden de paz, la seguridad jurídica y con avances reales y sólidos para el futuro del propio respeto de los Derechos Humanos.

Al contrario de lo que se pretende construir, que es crear un orden de respeto de los derechos y de paz, con las tendencias ideológicas en desarrollo, al menoscabar o despreciar la juridicidad objetiva que debe tener siempre el Derecho Internacional, y que debe respetar la soberanía del estado de derecho interno del Estado, se pierde la certeza jurídica. Al incorporarse el efecto de la errada subjetividad ideológica, con su disfraz de nueva justicia y postmodernidad, la antijuridicidad que trae envuelta erosiona, primero, y destruye finalmente el estado de derecho. Los que impulsan este nuevo horizonte 
lo presentan como última expresión de democracia, libertad y derechos de los hombres y mujeres. Y no se percatan que no lo es. No es una forma democrática de crear derecho en un Estado, sino escamoteando la democracia representativa; es imposición de poder foránea: ni es derecho lo que impone, sino arbitrio subjetivo de quienes detentan circunstancial, burocrática o políticamente ese poder.

\section{TRANSFORMACIÓN Y CONFUSIÓN DEL DERECHO INTERNACIONAL}

El proceso se desarrolla aceleradamente en todo el orbe, y de él sólo se escapan los Estados que detentan un gran poder y que perciben el peligro que representan para su soberanía, integridad y futuro, y su identidad nacional, estas nuevas tendencias e instituciones internacionales. Por ello, no se hacen parte en aquellas convenciones -vr.gr., como sucede con la CPI-, ni aceptan su competencia. (sin perjuicio, por cierto, de impulsar a veces, discrecionalmente, que se apliquen a otros Estados que tampoco reconocen las ni son parte en ellas. Lo que confirma que no es un orden de derecho el que se está transformando, sino de poder).

Al iniciarse la segunda mitad del siglo xx, dentro del cuadro de la ONU, como consecuencia de las pugnas ideológicas del bloque soviético con las potencias occidentales, del proceso de descolonización y de los intereses contrarios de los nuevos Estados independientes, y de la creciente diversidad cultural, desarrollo económico, social y tecnológico de los pueblos participantes, la costumbre internacional consolidada dejó de ser ahora universalmente aceptada. Aparece así una primera forma de evolución en el intento de ir a una codificación de la costumbre, en grandes convenciones multilaterales.

Charles de Visscher presenta este fenómeno y algunas de sus consecuencias en un artículo de la Reveu General de Droit International Public: 
"La observación demuestra que la contribución respectiva de la costumbre y del tratado al desarrollo del derecho internacional es tributario, por una parte, de las transformaciones del poder y, por otra, de la intensidad y de la complejidad de las relaciones internacionales" ${ }^{2}$.

En su análisis reconoce la evidente superioridad de la costumbre por su estrecho contacto con la realidad, sobre la reglamentación puramente convencional. No obstante, reconoce sus deficiencias, la incertidumbre inherente a su forma de expresión en la inestabilidad, heterogeneidad de concepciones morales y jurídicas de las diferentes culturas. Y frente a ello reconoce que la mayor precisión del texto del tratado presenta una ventaja. Pero -y ya en el tiempo que escribe su artículo, hace medio siglo atrás- observa la debilidad y peligro que estas convenciones suelen tener, a causa -anota- de:

"una propensión a las anticipaciones contractuales,... "a la vía de las planificaciones inspiradas por la ideología o por el espíritu del sistema." "Hay muchas pruebas recientes de las peligrosas facilidades que ofrece el tratado a unas iniciativas precipitadas y superficiales"3.

Respecto a las convenciones de carácter normativo elaboradas en el seno de las Naciones Unidas, concluye que "son ampliamente influenciadas por las exigencias de una participación que contempla la universalidad. Lo que resulta de eso es una cierta tensión entre el objetivo de la reglamentación que es la uniformidad y la diversidad muchas veces profunda de los intereses, de las costumbres o tradiciones de los participantes". Y agrega: "[...] se ha llegado a reconocer los peligros que configura para el Derecho Internacional la búsqueda de una unanimidad que no podría establecerse sino sobre la base de fórmulas ilusorias o al precio de concesiones lamentables" ${ }^{4}$.

Una constatación, posterior en medio siglo, permite anotar que ello ha conducido muchas veces a que la convención se hace imprecisa,

2 De Visscher, Charles, "Coutume et Traité en Droit International Public", en Revue General de Droit Internacional Public, Julio-Septiembre 1955, n³, separata, Editions A. Pedone, Paris, 1955, p. 1. 3 De Visscher, 1955, p.2.

4 De Visscher, 1955, p.3. 
plagada de vaguedades, más dada a indicar propósitos o ideas generales o sólo principios que suelen contradecir otros principios fundamentales del Derecho Internacional, que aun carecen del rigor jurídico que requiere una norma de derecho. Todo lo cual deja abierta su interpretación a la subjetividad del intérprete -sea este un Estado, un tribunal, o un publicista-. Y por ese enorme boquete el nuevo derecho pierde objetividad jurídica.

Tratadistas de reconocida categoría internacional, aun de escuelas o tendencias doctrinarias diferentes, han observado con preocupación que anteponer principios a normas consolidadas, y entregar primacía a la subjetividad, y a fines sobre la juridicidad va a privar al orden jurídico de la certeza y seguridad que debe configurar.

Es del caso recordar el razonamiento jurídico que llevó a la redacción del artículo $38^{\circ}$ del estatuto de la Corte Internacional de Justicia, fijando al tribunal la precedencia que debe considerar al fallar, en cuanto a la norma de derecho que debe preferir y aplicar: a) tratado; b) costumbre; y c) principios generales de derecho. La razón jurídica de preferir ese orden de precedencia es ser la norma convencional expresa y especial, en tanto la norma de costumbre es siempre más general, y los principios, que muchas veces subyacen y han inspirado normas de derecho, son siempre más generales aún.

Giorgio del Vecchio, filósofo del derecho de la escuela de Roma, no obstante concebir con gran amplitud los principios de derecho, y referir los principios racionales a los del derecho natural, previene -ya en una primera lección en la Universidad de Roma, en 1920- contra el peligro de la subjetividad, que suele -dijo- "otorgar reconocimiento y aplicación a principios que están en contradicción con el sistema de legislación del país. Es viciado, -añade-, aplicar un principio general en contradicción con un principio particular" 5 .

5 Del Vecchio, Giorgio, Los Principios Generales del Derecho, $3^{\mathrm{a}}$ ed., Bosch Casa Editorial, Barcelona, 1979, p. 25. 
Exige considerar un requisito formal de congruencia con el conjunto de la legislación, pues sin él, esta dejará de ser "un todo único, homogéneo, un verdadero organismo capaz de administrar una norma segura, no ambigua y menos contradictoria" ${ }^{6}$.

"Los principios, en cuanto presupuestos tácitos de las normas de derecho, tienen como función entregar a la reflexión crítica y filosófica el verdadero sentido jurídico de las normas de derecho [...] No al extremo de negar lo que determina la ley, o de contradecirla, pues la ley tiene su propia soberanía" ${ }^{7}$.

Agrega: "Tales principios, a pesar de tener un carácter ideal y absoluto, por consecuencia del cual superan virtualmente el sistema concreto del que forman parte, no pueden prevalecer contra las normas particulares que lo componen, ni destruirlas en ningún caso" 8 .

Del Vecchio señala dos ejemplos, que aun hoy día deberían ser considerados.

"Constituye, por ejemplo, un principio general de derecho, la validez de los pactos libremente consentidos; mientras una norma particular establece que a la acción nacida de tales pactos puede oponerse la prescripción, cuando haya transcurrido un determinado lapso de tiempo" 9 .

"El principio de la imposibilidad jurídica de imponer a los individuos limitaciones no fundadas en la ley, es absoluto en todo ordenamiento jurídico que ha asumido la forma de estado de derecho" ${ }^{10}$.

Es importante traer a colación estas afirmaciones, fundadas jurídicamente, por cuanto tocan precisamente en el vicio de antijuridicidad o ilicitud que está afectando la coherencia del Derecho Internacional y muy seriamente el estado de derecho interno.

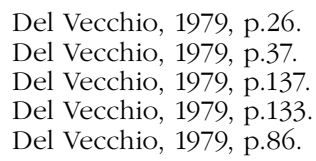


Alfred Verdross, eminente tratadista de la escuela de Viena, en la última edición de su Tratado de Derecho Internacional Público ${ }^{11}$, medio siglo más tarde, contiene aspectos relevantes atingentes a la tesis que este artículo plantea.

Aun cuando valora profundamente la existencia, validez y jerarquía jurídica de los principios generales de derecho, precisa tres aspectos esenciales que cabe considerar:

a) Sostiene que el artículo $38^{\circ}$ del estatuto de la Corte Internacional de Justicia se refiere "única y exclusivamente a aquellos principios fundados en ideas jurídicas generales, aplicables a las relaciones entre Estados"12.

b) Sólo cabe considerar como tal un principio que sea reconocido en los principales sistemas jurídicos del mundo.

c) Que los Estados son libres mientras no tengan obligaciones jurídicas expresas. En caso de duda se presume siempre la libertad de los Estados (es interesante al respecto la cita a RicciBusatti coincidiendo en su afirmación; y la sentencia en el caso del Lotus: "Restrictions upon the Independence of States cannot be presumed") ${ }^{13}$.

Por otra parte, Verdross afirma: "el hecho de que con arreglo al Derecho Internacional común, sólo existen deberes entre Estados particulares" [...]." De ahí que si se produce una infracción del Derecho Internacional no puede en principio protestar un órgano central de la comunidad de los Estados ni un Estado cualquiera, sino únicamente el Estado lesionado. Esto prueba que los deberes jurídicos internacionales sólo se dan en principio en la relación de los Estados interesados entre sî" ${ }^{14}$.

\footnotetext{
11 Verdross, Alfred, Tratado de Derecho Internacional Público, $6^{\mathrm{a}}$ ed., $2^{\mathrm{a}}$ reimpresión, Aguilar, Madrid, 1980.

12 Verdross, 1980, p.134.

13 Verdross, 1980, p.133.

14 Verdross, 1980, p.108.
} 
Reconoce que otra cosa ocurre en el Derecho Internacional organizado de la onu pero lo precisa y circunscribe a sus atribuciones estatutarias; y así lo indica: "reconoce deberes para con la comunidad, protegidos por sanciones colectivas [...] Figura, ante todo, la prohibición del recurso a la fuerza, cuya violación obliga al Consejo de Seguridad a intervenir (artículo 39 ${ }^{\circ}$ de la Carta). En cambio, el Consejo de Seguridad no tiene facultad para dictar una sanción contra un Estado que haya violado otra norma del Derecho Internacional" ${ }^{15}$.

No obstante, advierte sobre la verdadera naturaleza jurídica de diferentes materias en este nuevo orden creado en la onu y señala que el principio del respeto a los Derechos Humanos, proclamado por la Carta en el preámbulo, significa un deber moral de los Estados. Es un principio internacional encomendado a la regulación jurídica interna del Estado. Asimismo, lo es la propia Declaración Universal de los Derechos Humanos, aprobada el 10 de diciembre de 1948 por la Asamblea General, ya que esta carece de competencia legislativa y sólo puede hacer recomendaciones. En cambio, es vinculante jurídicamente para los Estados parte el Pacto de Derechos Civiles y Políticos, aprobado por la Asamblea General el 16 de diciembre de 1966, pues este fue ratificado posteriormente por numerosos Estados (al reunir el número de ratificaciones exigidas, entró en vigor el 26 de Mayo de 1976) ${ }^{16}$. Para Chile, comenzó a regir con su publicación en el Diario Oficial sólo en 1989.

Estas observaciones de Verdross, ratificadas en su nota a la tercera edición de la traducción al español de su obra, inducen a reflexionar en relación con la advertencia sobre la pérdida de juridicidad que evidencian los casos y ejemplos que se exponen a continuación.

Existen tres axiomas jurídicos esenciales que se deben respetar para que el derecho sea un orden racional. Uno es que los tratados, consensuados y ratificados por los Estados, son vinculantes y obligatorios para ellos. Otro es que toda norma de Derecho Internacional 
convencional que limita el ejercicio discrecional de la soberanía del Estado, debe ser siempre interpretada restrictiva y precisamente ${ }^{17}$. Y un tercer axioma es que si un tratado posterior interpreta, complementa o desarrolla un tratado anterior, esa interpretación es obligatoria para el Estado parte en ambos tratados. Y también, por cierto, para todo tribunal de derecho.

La advertencia sobre la pérdida de juridicidad, que pretende este artículo, se confirma con los ejemplos ofrecidos, que revelan la erosión ya producida al derecho aplicado tanto por tribunales internacionales, como también por los tribunales superiores de un Estado.

\section{EJEMPLOS}

\section{CORTE INTERAMERICANA DE DERECHOS HUMANOS}

(Sentencia en el caso Almonacid y otros versus Chile, 26 de septiembre 2006, que continúa la línea de razonamiento inaugurada en la sentencia en el caso Barrios Altos versus Perú, 14 de marzo de 2001).

En ambas sentencias la Corte determinó: "son inadmisibles las disposiciones de amnistía, las disposiciones de prescripción" [...] "Como consecuencia de la manifiesta incompatibilidad (con la Convención Americana de Derechos Humanos) las mencionadas leyes carecen de efectos jurídicos"18.

El fundamento para estas afirmaciones sigue un razonamiento que se basa sólo en apreciaciones subjetivas, sin intentar siquiera precisar normas de derecho que sean aplicables al caso, que sustenten tal predicamento. Al respecto, y en la imposibilidad de citar aquí otras

\footnotetext{
$17 \quad$ Verdross, 1980, p.489.

18 Corte Interamericana de Derechos Humanos, "Almonacid Arellano y otros vs. Chile", sentencia de 26 de septiembre de 2006, párr..44, p.9.
} 
de una muy extensa sentencia, es sugerente una cita más, que realza el voto razonado de uno de los jueces que concurrió a ella. Dice:

"Las leyes permanecen idénticas a sí mismas, mientras por debajo de ellas fluye el curso siempre nuevo de la historia y de la vida" ${ }^{19}$.

Con ese concepto, la sentencia contradice normas de derecho expresas y vigentes; se aparta de toda juridicidad objetiva e incurre en un abuso del derecho para seguir el curso subterráneo de su subjetividad.

\section{Antecedentes De Derecho QUE LAS SENTENCIAS No CONSIDERAN}

a) La Convención Americana de Derechos Humanos, que crea la Corte y regula sus funciones, no contiene disposición alguna que prohíba la prescripción o la amnistía ni que le permita determinar que esas leyes de un Estado parte carecen de efecto jurídico.

Más aún, la propia Convención, expresamente, admite la amnistía al igual que el indulto. En efecto, la disposición del artículo $4^{\circ} \mathrm{n}^{\mathrm{o}} 6$ señala el derecho de toda persona condenada a muerte a solicitar la amnistía, el indulto o la conmutación de la pena capital y agrega, textualmente: "las cuales podrán ser concedidos en todos los casos".

Es decir, la sentencia en cuestión no sólo ignora el texto de la Convención que la creó y la regula, sino que abroga un derecho humano esencial que aquella otorga a todo condenado. Aun al condenado por los más graves crímenes y que ha sido condenado a la mayor pena posible. Con tanto mayor razón debe y puede beneficiar la amnistía - "en todos los casos"- a un condenado (o procesado) a una pena menor; y también puede ser beneficiado con el indulto. Asimismo, no cumple con las garantías procesales que fija la Convención (art. 8.1) a toda 
persona "en la sustanciación de cualquier acusación penal en contra de ella" ; "derecho a ser oída [...] por un juez o tribunal competente [...] establecido con anterioridad por la ley"; ni con los derechos que reconoce a todo procesado, precisamente acorde a los principios de legalidad, irretroactividad de la ley penal, pro reo, y ne bis in idem. (art. $9^{\circ}$ ).

b) El Pacto Internacional de Derechos Civiles y Políticos, aprobado en 1966, y que entró en vigor al ser ratificado por el número de Estados requerido el 23 marzo 1976, está vigente para Chile desde 1989. Dicho pacto regula como normas de derecho vinculante para los Estados parte, propósitos y principios contenidos en la Declaración Universal de Derechos Humanos, aprobada por la Asamblea General en 1946. Y también viene a precisar y desarrollar los propósitos y principios de la Convención Americana de Derechos Humanos (o "Pacto de San José).

Es importante destacar que PIDCP, contiene entre sus disposiciones normas de derecho específicas que, junto con confirmar la plena validez de la supremacía constitucional y soberanía del Estado y de su legislación interna (es decir, del estado de derecho), evidencia que los propósitos y principios de las Declaraciones de Derechos Humanos no son normas de derecho que rijan ni se apliquen directamente con relación ni dentro de un Estado. Ni mucho menos, que puedan abrogar sus leyes internas o hacer que carezcan de efectos jurídicos.

Artículo $2^{\circ} \mathrm{n}^{\circ}$ 2: "Cada Estado parte se compromete a adoptar, con arreglo a sus procedimientos constitucionales y a las disposiciones del presente pacto, las medidas que considere oportunas para dictar las disposiciones legislativas o de otro carácter, que fueren necesarias para hacer efectivos los derechos reconocidos por el presente Pacto y que no estuvieren ya garantizadas por disposiciones legislativas o de otro carácter".

Para comprender hasta el extremo que el subjetivismo ideológico induce a incurrir en el vicio de la anti-juridicidad es necesario precisar tres citas breves de disposiciones del Pacto, vigente y norma de 
derecho especial, que regula los propósitos y principios generales de Derechos Humanos.

Artículo $6^{\circ} \mathrm{n}^{\circ}$ 4: "Toda persona condenada a muerte tendrá el derecho a solicitar el indulto o la conmutación de la pena de muerte. La amnistía, el indulto o la conmutación de la pena capital podrán ser concedidas en todos los casos".

Artículo $14^{\circ} \mathrm{n}^{\circ}$ 7: "Nadie podrá ser juzgado ni sancionado por un delito por el cual haya sido ya condenado o absuelto por una sentencia firme de acuerdo con la ley y el procedimiento penal de cada país."

Artículo $15^{\circ} \mathrm{n}^{\circ}$ 1: "Nadie será condenado por actos u omisiones que en el momento de cometerse no fueran delitos según el derecho nacional o internacional. Tampoco se impondrá pena más grave que la aplicable en el momento de la comisión del delito. Si con posterioridad a la comisión del delito la ley dispone la imposición de una pena más leve, el delincuente se beneficiará de ello."

Resulta evidente que ninguna de las citadas disposiciones, que son normas convencionales de Derecho Internacional vigentes, vinculantes para un Estado parte -y Chile lo es desde 1989-, fue considerada, ni respetada por la Corte Interamericana de Derechos Humanos, en su sentencia. Pero, más aún, junto con negar la validez del ordenamiento jurisdiccional del Estado -"las leyes de prescripción o amnistía carecen de validez jurídica”, afirma la sentencia-, rechaza las normas que fijan el principio pro reo, y todavía determina que el Estado debe dejar sin efecto la sentencia que aplicó la amnistía, resolución que alcanzaba ya la categoría de cosa juzgada ${ }^{20}$.

En pocas palabras, la sentencia no sólo no acató la limitación temporal que había fijado el Estado de Chile al admitir la competencia de la Corte -sólo respecto de delitos cuyo comienzo de ejecución fuera posterior al mes de abril de 1990-, ${ }^{21}$ y se arrogó competencia para

\footnotetext{
20 Sentencia "Almonacid", 2006, párrafos 146 y147, p.59.

21 Sentencia "Almonacid", 2006, párrafo 42, p.9, recoge el texto de la declaración del Gobierno de Chile al reconocer la competencia de la Corte, el 21 de Agosto de 1990: (...) "el Gobierno de
} 
juzgar, calificar retroactivamente el delitos e inculpar a los autores por hechos ocurridos en 1973; se arrogó atribuciones para no acatar - o violar más precisamente- las disposiciones ya citadas del Pacto; para ignorar derechos humanos de los procesados, que reconoce la propia Convención, como son los beneficios de los principios de legalidad, por reo, irretroactividad de la ley penal, cosa juzgada, prescripción y el derecho a la amnistía; y se arroga una atribución inadmisible, para determinar que el Estado debe asegurar que se reabra el proceso, y debe asegurar que no se aplique nunca más la amnistía y se derogue la ley ${ }^{22}$.

Un corolario lamentable, es que la Corte Suprema acogió la antijuridicidad, y ordenó reabrir la causa, dejando sin efecto la cosa juzgada. Sin entrar a calificar lo indicado, al menos confirma la advertencia que se formula: la juridicidad está siendo gravemente erosionada, en esta encrucijada creada por el subjetivismo y la neo-ideología "creacionista", que se considera liberada del orden jurídico propio del Derecho Internacional y también del estado de derecho propio del Estado.

c) La sentencia en cuestión, en sus razonamientos, pretende justificar sus decisiones que no puede apoyar en el derecho, recurriendo, por una parte, a opiniones meramente políticas: una, calificar de "autoamnistía" la norma legal establecida por el Estado; y dos, negarle validez por ser un decreto-ley.

Pero en su subjetividad señala que son una "afrenta inadmisible al derecho a la verdad y al derecho a la justicia" 23 (las opiniones razonadas de uno de los jueces en su voto concurrente, hacen innecesario un mayor análisis de dicha subjetividad, total y absolutamente antijurídica).

\footnotetext{
Chile deja constancia que los reconocimientos de competencia que ha conferido se refieren a hechos posteriores a la fecha de depósito de este instrumento de ratificación o, en todo caso a bechos cuyo principio de ejecución sea posterior al 11 de marzo de 1990"..

22 Sentencia "Almonacid", 2006, párrafo 146, p.59 y párrafos 151 y 152, p.60.

23 Sentencia "Almonacid", 2006, voto razonado Juez Cançado, párrafo 12. P.5.
} 


\section{IMPOSICIÓN DEL IUS COGENS}

La sentencia, por otra parte, recurre o admite opiniones que sostienen que la prescripción y amnistía son inadmisibles, por que violan normas de ius cogens. Pero, no obstante que cita en un pretendido apoyo el artículo $53^{\circ}$ de la Convención de Viena sobre el Derecho de los Tratados, elude mencionar el efecto preciso que dicho artículo establece: que no es otro que la nulidad del tratado. Como esa disposición es inaplicable en la especie, recurre al eufemismo de sostener que tales leyes carecen de eficacia jurídica!

El absurdo a que lleva la pretensión de la sentencia -y que confirma su antijuridicidad-, podría significar que la amnistía, la prescripción, y los principios jurídico-penales que fijan las ya citadas disposiciones de la Convención Americana de Derechos Humanos y del Pacto de Derechos Civiles y Políticos, y que serían normas contrarias al ius cogens, según afirma la Corte, de atenerse al artículo $53^{\circ}$, acarrearían la nulidad absoluta de tales tratados. Tal absurdo no lo podría concebir nadie; pero, en forma definitiva, confirma que la sentencia carece de consistencia jurídica.

El razonamiento de la sentencia para determinar y calificar como crimen de lesa humanidad el homicidio cometido en 1973, imputado a los procesados, obedece al propósito de sostener que son inadmisibles el derecho a la amnistía de 1978, y a la prescripción, no obstante ser normas legales garantizadas por los tratados ya indicados y por la Constitución y el derecho penal de Chile (aun cuando Chile no otorgó competencia a la Corte, en 1990, sino para crímenes cuyo principio de ejecución fuera posterior a esa fecha, igual entró a calificar retroactiva y arbitrariamente hechos anteriores al límite temporal fijado).

La subjetividad de tal decisión -y su anti-juridicidad- es evidente y total. Baste considerar algunos hechos que constan en la propia sentencia, y que indican lo contrario de lo que establece. 
a) Sostiene que la víctima fue "ejecutado extrajudicialmente por agentes del Estado" ${ }^{24}$.

b) Incluye un único testimonio presencial: el de la viuda de la víctima. De la declaración que transcribe, se puede extraer los siguientes puntos:

1) Que su esposo, que no se alojaba en la casa "por razones de seguridad" fue a visitarla el 16 de septiembre de 1973;

2) Que a las 11,30 horas llegó una patrulla de carabineros a buscarlo y lo sacaron;

3) Que "a la esquina de la casa, en el tumulto vio que su marido trastabilló;

4) Que "sintió" la ráfaga de la metralleta [...] eran dos carabineros que iban con él;

5) Que cayó herido de muerte ya, pero quedó herido;

6) Que el sargento fue a buscar una camioneta y llegaron más carabineros;

7) Que lo llevaron al hospital;

8) Que lo operaron, pero murió al día siguiente ${ }^{25}$.

La calificación jurídico-penal de este hecho, en caso alguno justifica la calificación que hace la sentencia. Más aún si se ponderan equilibradamente algunas afirmaciones. Así, el punto 1) sugiere que había optado por estar en "clandestinidad", no obstante saber que debía presentarse ante Carabineros; el 2)," el tumulto”, que no precisa más, indica la llegada a la esquina de su casa de un grupo numeroso de personas presumiblemente para impedir su arresto. (Almonacid, dice la sentencia, era dirigente local del Partido Comunista, secretario provincial de la cuT), ¿motivó esta situación para que uno de los dos carabineros disparara una ráfaga, alcanzando una bala a la víctima? Que haya quedado herido, confirma esta tesis. Por su parte, lo indicado en los puntos 6), 7) y 8) revelan el interés de salvar su vida, siendo esos esfuerzos lamentablemente frustrados.

24 Sentencia, 2006, en "Consideraciones de la Corte". P.43 y sgntes., "A) "Respecto a la aplicación del DL 2191": a) La ejecución extrajudicial del sr. Almonacid Arellano."

25 Sentencia, 2006, párrafo 72, P.20, "a) Declaración de Eliana Gómez Olmos, esposa de Luis Alfredo Almonacid Arellano.” 
La sentencia no analiza lo que contiene esta declaración, de la propia querellante, y que motivó que los Tribunales chilenos, un Juzgado -que admitió la querella interpuesta en noviembre 1992, 19 años después del hecho-, la Corte de Apelaciones y la Corte Suprema -que rechazó el último recurso de casación-, calificaron este delito como homicidio. La sentencia desarrolla una versión diferente de los hechos. De hechos ocurridos el 16 de septiembre de 1973, que Chile expresamente dejó fuera de la competencia de la Corte, al reconocer a ese Tribunal internacional. El abuso de poder que ello implica, se aumenta al violar las normas básicas del debido proceso, e imputarles a los inculpados, que no son oídos en el juicio, un delito diferente, e imputarles reiteradamente responsabilidad en un hecho inexistente: ser culpables de la "ejecución extrajudicial” de la víctima ${ }^{26}$.

Al efecto, y con el fin de sustentar la calificación que hace del hecho, en diversos párrafos discurre sobre bases absolutamente desligadas del asunto litigioso. Así, por ejemplo, hace referencia al estatuto del Tribunal Militar Internacional de Nuremberg, anexado al Acuerdo de los Estados vencedores para juzgar y castigar a los principales criminales de guerra del Estado vencido (1946). Y, asimismo, -dice- "al asesinato", codificado en el Estatuto Militar Internacional de Tokio, igualmente de cinco Estados vencedores para el juzgamiento de los principales criminales de guerra del "Lejano Oriente" (su relación con el caso Almonacid y otros, es por lo menos sorprendente).

Pero, -y configura un caso preciso de jurisprudencia "creacionista", aunque gravemente antijurídica-, es la conclusión que extrae la Corte de una afirmación igual de arbitraria que hizo el TMI: indicó que el estatuto que le dio origen "es la expresión del Derecho internacional existente en el momento de su creación". Y la Corte concluye: "con ello reconoció la existencia de una costumbre internacional,

26 Sentencia, 2006, "C) Valoración de la prueba". P.20 y signtes. "b) Antecedentes: hechos ocurridos antes de 21 de Agosto 1990"; ii) La ejecución del sr. A. Almonacid y la iniciación del proceso penal seguido por ese hecho." Párrafos 82.8 y 82.9, P.29. 
como una expresión del Derecho internacional que prohibía esos crímenes" ${ }^{27}$.

No parece consistente la conclusión de la sentencia con la realidad histórica del derecho en los Estados que crearon dicho Estatuto, ni menos aún con las citas que se hacen en la propia sentencia del caso Almonacid, que aparece vinculado a la mayor catástrofe bélica del planeta. Una de las citas detalla la agresión armada de la u.R.s.s a Estonia, en 1939, que significó la pérdida de su independencia. Dice: "El régimen totalitario comunista condujo acciones sistemáticas contra la población de Estonia, incluyendo, por ejemplo, la deportación de cerca de 10.000 personas el 14 de junio de 1941 y más de 20.000 el 25 de mayo de 1949" 28 .

¿Acaso esa conducta del Estado que suscribió ese Estatuto e integró el Tribunal Militar de Nuremberg, reconocía el Derecho Internacional que se supone existía en esa fecha y con ello reconocía la existencia de una costumbre internacional que prohibía tales crímenes? (Pudo agregar iguales casos con Letonia y Lituania, en 1939, y la guerra de agresión contra Finlandia, en 1940; y, por cierto, los 12 o 20 mil oficiales polacos - prisioneros de guerra no declarada por la U.R.s.s- masacrados en el bosque de Katyn, en 1941).

La sentencia dedica extensas párrafos a las guerras internacionales o a guerras internas en diferentes partes del mundo. Pero no destina ni una sola línea para analizar lo que efectivamente ocurrió en Chile en 1973. Cita el informe de la Comisión de Verdad y Reconciliación, pero omite toda referencia a los aspectos que ella contiene en su segunda parte, Capítulo I , en la que explica la realidad confrontacional existente en el país, que dividía a la población civil e impulsaba eventualmente a una guerra civil. Omite también los enfrentamientos entre grupos revolucionarios clandestinos armados y las Fuerzas Armadas y Carabineros.

\footnotetext{
27 Sentencia, 2006, párrafo 97, P.45.

28 Sentencia,2006, párrafo 100, cita 126, P.46.
} 
La situación de violencia, por parte de grupos civiles, le existencia de miles de individuos armados y organizados para imponer la revolución y la toma del poder total, creó una situación tal que todos los órganos constitucionales del Estado, Congreso Nacional, Poder Judicial, Contraloría General de la República y las entidades más representativas de los profesionales, denunciaron la ilegitimidad de ejercicio en que había incurrido el Gobierno, al violar reiteradamente la Constitución y la deliberada destrucción del Estado de derecho en Chile.

La amenaza cierta del estallido de la guerra civil provocó la intervención militar de las Fuerzas Armadas y de Orden el 11 de septiembre de 1973.

Una declaración del ex Presidente del Senado, don Patricio Aylwin Azocar (quien asumiría la Presidencia de la República en 1990) señaló, el 19 de octubre de 1973 lo siguiente: "La verdad es que la acción de las Fuerzas Armadas y del Cuerpo de Carabineros no vino a ser sino una medida preventiva que se anticipó a un autogolpe de Estado que, con la ayuda de las milicias armadas con enorme poder militar de que disponía el Gobierno y con la colaboración de no menos de 10.000 extranjeros que había en este país, pretendía o habrían consumado una dictadura comunista" 29.

La cita anterior aparece confirmada en el informe al pleno del partido Comunista de Chile de Agosto de 1977, de su Secretario General Luis Corbalán. En él señala: "nos preocupamos desde 1963, de la preparacion militar de miembros del partido, no para derribar al gobierno de turno que era el de Alessandri, ni al siguiente que era el de Frei, sino para contribuir al defender las conquistas del pueblo chileno que, estabamos convencidos, alcanzaría el poder [...] después de las elecciones de Marzo de 1973 estaba claro que la reacción buscaría el derribamiento del Gobierno a través del golpe de Estado, lanzamos la consigan de 'No a la guerra civil' y simultáneamente intensificamos la preparación combativa de aquellos militantes que ya 
trabajaban en este frente y los pertrechamos del algún armamento. [...] por aquellos días la Central Unica de Trabajadores llamó con apoyo de Comunistas y Socialistas a la formación de las comisiones de defensas de las industrias [...] y al mismo tiempo convertir dichas comisiones en unidades de combate, de hecho Milicias Obreras, para defender al Gobierno ante la eventualidad de una agresión reaccionaria. Alrededor de 10.000 obreros alcanzaron a organizarse". [...] La preparación que en este terreno habia en la clase obrera y la que tenian algunos partidos, especialmemte nosotros y los socialistas podria haber sido útil y ya casi decisiva para conjurar un golpe de tipo tradicional, pero no el que se dió. [...] el plan de los contrarevolucionarios, con la asesoría de la cia fue concebido y ejecutado de manera tal, que les permitió, en horas, controlar la situación y desarticular el movimiento popular.

Numerosos de nuestros compañeros, y militantes de otros partidos y sin partidos, se batieron guiados por su propia, heroica y respetable decisión. Objetivamente no fue posible organizar una resistencia vertebrada" 30 .

La sentencia tampoco considera que la participación directa, encubierta o clandestina (eventual), en las hostilidades de personas, civiles, es una materia trascendente en el derecho internacional humanitario, que altera la condición y protección del individuo ${ }^{31}$.

El arresto del señor Almonacid por Carabineros, frustrado el 14 de septiembre de 1973, por estar oculto fuera de su casa y llevado a cabo al sorprenderlo en ella el 16 de septiembre, se explica dada su condición de dirigente regional del Partido Comunista y de secretario

\footnotetext{
30 Corvalán, Luis, "La Revolución Chilena, la Dictadura Fascista y la Lucha por Derribarla y crear una Nueva Democracia". "Informe al Pleno, de Agosto de 1977, del Comité Central del Partido Comunista de Chile, rendido por su Secretario general, compañero Luis Corvalán.” 2a Parte. Impreso de 8 páginas sin pie de imprenta.

31 Melzar, Nils, "Guía para Interpretar la Noción de Participación Directa en las Hostilidades, según el Do.I.H.”, Comité Internacional de la Cruz Roja, Ginebra, Suiza. P-12, 41 y sgnts., diciembre 2010 .
} 
provincial de la cut en la Provincia de O’Higgins, como la propia sentencia certifica ${ }^{32}$.

\section{Efectividad del Ius Cogens en el Derecho Internacional}

La efectividad del ius cogens en el Derecho Internacional es una cuestión muy compleja, difícil de precisar fuera del ámbito del derecho de los tratados. Y aún en ese caso, la definición del artículo $53^{\circ}$ de la Convención de Viena, en verdad que no aclara definidamente el asunto.

La doctrina, que ha intentado dilucidar jurídicamente, y no ideológicamente la cuestión, no es uniforme.

Verdross estima que son normas de ius cogens, los principios propios del Derecho Internacional que señala la Carta de las Naciones Unidas. Y la razón jurídica que sustenta tal opinión, es el artículo $103^{\circ}$ de la Carta de la onu, que establece:

"En caso de conflicto entre las obligaciones contraídas por los Miembros de las Naciones Unidas en virtud de la presente Carta y sus obligaciones contraídas en virtud de cualquier otro convenio internacional, prevalecerá las obligaciones impuestas por esta Carta" ${ }^{33}$.

De manera que dicha contradicción entre disposiciones de un tratado y las que fija la Carta, hace prevalecer a la Carta. Una vez más, al igual que en el artículo $53^{\circ}$ de la Convención de Viena, la disposición se remite en sus efectos -propios del jus congens-, sólo a tratados, y no lo concibe en la costumbre.

Verdross, que analiza con prudencia y sentido jurídico esta materia, conduce a fijar, en consecuencia, como normas de ius cogens, con categoría jurídica como para prevalecer sobre cualquier tratado, aún de fecha posterior y de especialidad, los siguientes principios: 
1. Independencia de los Estados

2. Igualdad soberana de los Estados

3. Libre determinación de los pueblos

4. No intervención en los asuntos que son de jurisdicción interna de los Estados

5. Prohibición del uso de la fuerza, exceptuando la legítima defensa

6. Solución pacífica de controversias

7. Respeto de los derechos humanos fundamentales

Por tanto, siendo congruentes las disposiciones del artículo $103^{\circ}$ de la Carta, y los artículos $53^{\circ}$ y $64^{\circ}$ de la Convención de Viena, el efecto de nulidad que sancionan estos últimos, sólo alcanza a un tratado; a cualquier tratado que estuviese en contradicción con alguno de los principios recién indicados.

Lo anterior pone en tela de juicio que exista efectivamente una norma de ius cogens que prohíba aplicar la jurisdicción penal interna de un Estado $-y$, por ende, sus normas legales de prescripción y de amnistía-, sin violar los principios indicados en los números 1, 2, 3 , 4 y 5 , que preceden. La sanción, a todo tratado que pretenda hacerlo, es la nulidad. Con esta concepción y precisión jurídica fundada respecto al ius cogens, carece de racionalidad suponer que el Estatuto del Tribunal Militar de Nuremberg, fijado por los Estados vencedores en una guerra -en la que Chile no participó-, sea vinculante para un Estado que no es ni fue parte de ese acuerdo; y mucho menos que una supuesta norma de costumbre -no nata ni existente en la práctica de los Estados partícipes en el acuerdo- esté, aun hoy día, por encima de normas jurídicas específicas y especiales, vigentes, como las del Pacto Internacional de Derechos Civiles y Políticos, y de los principios esenciales recién citados.

A mayor abundamiento, debe considerarse, que las sentencias de tribunales internacionales o nacionales de un Estado, que con la intención subjetiva de favorecer el principio indicado en el número 7 , no respetan los cuatro primeros principios, no cumplen tampoco con el 7 , pues niegan el respeto a derechos humanos fundamentales 
de los procesados o condenados, derechos que reconocen tanto la Convención Americana de Derechos Humanos y el Pacto de Derechos Civiles y Políticos, como los Convenios de Ginebra y sus Protocolos, en su caso.

\section{CONVENIOS DE GINEBRA: DERECHO INTERNACIONAL HUMANITARIO Y JURISPRUDENCIA DE LA CORTE SUPREMA}

En caso de conflictos armados internos en el territorio de un Estado, que reúnen la magnitud y características para configurar una guerra civil o "guerra no internacional", como la definen los Convenios, se hace aplicable a esa situación diversas normas del Derecho Internacional Humanitario. Especial y precisamente el artículo $3^{\circ}$ común de los convenios, y el Protocolo II, adicional a los mismos.

Las tendencias cuyo subjetivismo tiende a utilizar las normas del D I H a situaciones de violencia o a actos de represión de órganos o funcionarios de un Estado, y a los delitos cometidos por ellos, en circunstancia que no concurren los requisitos que los convenios y el Protocolo II fijan para su aplicación, no sólo califican mal los hechos y los delitos, sino que aplican mal, arbitraria o abusivamente sus disposiciones.

Limitando las observaciones exclusivamente a la aplicación de las disposiciones convencionales efectuada por numerosas sentencias de la Sala Penal de la Corte Suprema, sobre la base fáctica, pero errada, de que en Chile hubo entre 1973 y 1989 un estado de guerra, equivalente a la "guerra no internacional", resaltan tanto errores graves en la aplicación de disposiciones, como en omisiones de parte de ellas, que alteran su significado, y no considerar otras vinculadas 
directamente; además, una interpretación inadecuada del Derecho Internacional ${ }^{34}$.

Artículo $3^{\circ}$ común. Concebido como un "mini convenio" en sí mismo, tiene por fin incorporar a un conflicto armado entre bandos organizados dentro del territorio de un Estado, las normas del derecho humanitario para la protección de las víctimas de la guerra. Con tal finalidad, prohíbe una extensa gama de delitos y crímenes que señala.

En muchas de aquellas sentencias condenatorias, a los procesados a los que se imputa responsabilidad en esos hechos ilícitos, sosteniendo que no es aplicable en tales casos ni la prescripción -largamente cumplidos los plazos legales-, ni la amnistía, también establecida en la ley penal chilena; no han considerado ni estudiado el inciso final del artículo $3^{\circ}$ común, que fija:

"La aplicación de las anteriores disposiciones no surtirá efectos sobre el estatuto jurídico de las partes en conflicto".

No parece ser jurídicamente posible, aplicar dicho artículo $3^{\circ}$ común, y no considerar en forma alguna el inciso final del mismo. Más aún, cuando éste deja en pié plenamente la validez del estatuto jurídico del Estado en conflicto. Es decir, en el caso concreto al que se aplica la sentencia condenatoria, las garantías constitucionales del artículo $19^{\circ} \mathrm{n}^{\circ} 3$, y las normas penales y procesales que la ley interna fija: la prescripción y la amnistía.

Protocolo II adicional a los convenios de Ginebra.

El artículo $1^{\circ}$, ámbito de aplicación material.

"1. El presente Protocolo, que desarrolla y complementa el artículo 3 común a los Convenios de Ginebra ... sin modificar sus actuales

\footnotetext{
34 Sentencias, Sala Penal Corte Suprema, 100 sentencias en materias relativas a violaciones de derechos humanos, entre 1973 y 1990. (vr.gr. SCS.de 13 marzo 2007, Rol no 3125-04; o SCS de 22,09,2010, Rol nº.760-09; o SCS de 27.01.2011).
} 
condiciones de aplicación, se aplicará a todos los conflictos armados [...] que se desarrollen en el territorio de una Alta Parte contratante entre sus Fuerzas Armadas y Fuerzas Armadas disidentes o grupos armados organizados que, bajo la dirección de un mando responsable, ejerzan sobre una parte de dicho territorio un control tal que les permita realizar operaciones militares sostenidas y concertadas y aplicar el presente protocolo".

"2. El presente protocolo no se aplicará a las situaciones de tensiones internas y de disturbios interiores, tales como los motines, los actos esporádicos y aislados de violencia y otros actos aislados que no son conflictos armados".

Las sentencias condenatorias no aceptan considerar aplicable el Protocolo II, por el hecho de no haber existido en Chile un conflicto armado de tal magnitud. Pero no han tenido en cuenta dos argumentos sustanciales: uno, que el Protocolo desarrolla y complementa el artículo $3^{\circ}$ común, lo que conduce a influir en la interpretación jurídica de aquel; y dos, que aquel último inciso del artículo $3^{\circ}$, también determina su aplicación, precisamente a que existan "Partes en conflicto". Y esas son las que necesariamente define el Protocolo II. Conclusión forzosa de ambas disposiciones: no cabe aplicar el artículo $3^{\circ}$ de los Convenios a una situación interna si no concurren los requisitos que prescribe el artículo $1^{\circ}$ del Protocolo II.

Las sentencias condenatorias aludidas, insisten, sin embargo, en aplicar el citado artículo $3^{\circ}$,-omitiendo su inciso final que reconoce el pleno imperio del orden jurídico interno-, y sin considerar el Protocolo que lo "desarrolla y complementa", lo que implica una interpretación no sólo sesgada y parcial, sino errónea y arbitraria de los textos interpretados, y, por ende, violatoria del derecho.

Resulta, además, que no se considera el artículo 6, que dispone que no se podrá invocar ninguna disposición con el objeto de menoscabar la soberanía de un Estado, como tampoco, para intervenir directa o indirectamente, en los asuntos internos o externos del Estado parte. 
Con todo, resulta incomprensible que no se considere, al sentenciar, las disposiciones del artículo $6^{\circ}$ del Protocolo II. En este, además de reiterarse los principios básicos del orden jurídico penal de los Estados civilizados -e incorporados constitucionalmente al estado de derecho interno- se fija que nadie será condenado por una infracción si no es sobre la base de su responsabilidad penal individual. Lo que en muchos casos no ha sucedido.

\section{Negativa A APlicar la Amnistía}

Más importante, aún, resulta la disposición del artículo $6^{\circ} \mathrm{n}^{\circ} 5$ :

"A la cesación de las hostilidades, las autoridades en el poder procurarán conceder la amnistía más amplia posible a las personas que hayan tomado parte en el conflicto armado o que se encuentren privadas de libertad, internadas o detenidas por motivos relacionados con el conflicto armado".

Las normas relativas a la interpretación de los tratados, que siempre deben cumplirse de buena fe, no pueden conducir a negar eficacia jurídica a las disposiciones citadas, y, en definitiva ignorarlas. Más antijurídico aún resulta, frente a todas ellas, afirmar que los convenios de Ginebra prohíben aplicar la amnistía y también la prescripción. Nada en aquellos lo establece ni puede lícitamente interpretarse contra su texto expreso.

\section{EL MITO DE LA IMPRESCRIPTIBILIDAD}

Se sostiene, asimismo, que el Derecho Internacional impone sobre el estado de derecho interno, y sobre los tribunales obligados a fallar en derecho, la obligación de declarar imprescriptibles los crímenes y delitos calificados acorde a un peculiar concepto de guerra, que no cuadra con la de los Convenios de Ginebra. Pero como en éstos no existe norma alguna que prohíba la prescripción -ni tampoco la amnistía-, se suele recurrir a una figura o ficción absolutamente antijurídica. 
Se cita, al efecto, la Convención sobre la imprescriptibilidad de los crímenes de guerra y de los crímenes de lesa humanidad, aprobada en 1968, que entró en vigor en 1970, pero que no es jurídicamente vinculante para Chile, que no la ha ratificado ni es parte de ella. Otro tanto han decidido casi dos tercios de los Estados existentes en el planeta. En efecto, de los 198 Estados independientes, solamente 54 Estados la han ratificado; y 144 no lo han hecho. Algunos de ellos no lo han hecho por que no es compatible con disposiciones del Pacto de Derechos Civiles y Políticos.

No obstante, diversas sentencias condenatorias, al igual que la Corte Interamericana, la citan, y luego, por una ficción carente de toda juridicidad, la suponen creadora de una norma de costumbre internacional. Es decir, suponen que un tercio de los Estados le imponen a los dos tercios restantes como supuesta costumbre internacional, un tratado que no han ratificado.

No se observa, tampoco, que aplicar en materia penal, una supuesta "costumbre" para condenar, abrogando de hecho el orden jurídico penal del Estado, está fuera de las atribuciones que la Constitución y las leyes dictadas conforme a ella, fijan a los Tribunales de Justicia. Por otra parte, el orden jurídico penal corresponde a la jurisdicción soberana del Estado, y que, como precisa Verdross: "las limitaciones impuestas a la libertad de los Estados tienen que interpretarse en sentido estricto" (32). Y no existe ninguna norma expresa de Derecho internacional, vigente y vinculante para Chile, que pueda imponer sobre el Derecho Penal nacional tal imprescriptibilidad a delitos cometidos hace más de treinta años atrás.

\section{ENCRUCIJADA A LA JURIDICIDAD}

El análisis efectuado hasta aquí es suficiente para apreciar cono las doctrinas creacionistas, las tendencias ideológicas y la subjetividad judicial, han llegado al extremo de afectar y erosionar la juridicidad tanto respecto al Derecho Internacional como al estado de derecho interno. Revelan cómo, selectiva pero también progresivamente, van destruyendo la consistencia jurídica en ambos planos. Los boquetes 
que se abren en el orden internacional, lo replican arbitrariamente en el orden del estado de derecho interno. En uno se tergiversan las normas convencionales, se ignoran, o se arrogan atribuciones que no tienen; en el otro, se interpreta mal el Derecho Internacional y se abroga ilegítimamente el derecho interno. Así lo evidencian los antecedentes y disposiciones expuestas anteriormente.

En defensa de las sentencias internacionales y nacionales, se sostiene -como en alguna de ellas se afirma-, que defienden "los fines del derecho". Y, entonces, se permiten tener la libertad y autonomía para fallar sin considerar las normas de derecho efectivas que contienen los propios tratados que se dice aplicar, y que contradicen su decisión; y a su vez, internamente, se interpreta mal el Derecho internacional y no se cumplen con rigor las normas constitucionales ni el derecho penal que el estado de derecho interno garantiza (33).

De esta manera, en vez de fortalecer los derechos, de acrecentar la certeza jurídica que debe garantizar el estado de derecho interno de la nación; y en vez de desarrollar el Derecho Internacional en términos de no atropellar la independencia, soberanía e igualdad de los Estados, se está configurando una anarquía en la que, por una parte, se crean entes que ejercen un poder arbitrario, por encima del derecho, en su subjetividad y funciones; y por otra, se consagra que sólo el poder discrimina y no subordina a los Estados a este nuevo orden.

Bastaría analizar con serenidad la carencia de fundamentación jurídica sólida tanto en algunas resoluciones de organizaciones internacionales universales -vr.gr. Consejo de Seguridad de Naciones Unidas-, o regionales -vr.gr. OEA-, para comprobar que se extralimitan en sus efectivas atribuciones o abiertamente violan su propia Carta constitutiva, para priorizar concepciones políticas o ideológicas por encima de los principios esenciales y del derecho.

Se alteran, asimismo, las normas de Derecho Internacional referidos a los principios o títulos de jurisdicción de los Estados, pretendiendo hacer primar -tergiversando la realidad- un no nato título absoluto de universalidad. Se pretende erradamente identificar como tal lo 
que corresponde a otros, sea los de protección, nacionalidad o personalidad pasiva, y aun de territorialidad, fijados en tratados especiales. Pero no es cuestión sólo de nombres. Lo grave es que detrás de esa pretendida universalidad se distorsiona el derecho y se erosiona la soberanía y la igualdad de los Estados. Y una vez más es el poder de los Estados -y su voluntad soberana-, la única valla sólida frente a esta nueva forma de intervencionismo foráneo.

En fin, son todos distintos síntomas de la encrucijada que se está forjando y amenazando la juridicidad, tanto en el orden de derecho internacional, como en el estado de derecho interno. El desafío es advertirlo, analizarlo y precaver los valores permanentes urbi et orbi, antes que la antijuridicidad avente, en una gran anarquía, el derecho que se ha intentado construir.

Un resumen final puede consistir en hacer una interpretación jurídica, racional y precisa del Derecho Internacional comprendido en la materia de esta advertencia.

Los tres tratados principales invocados, vinculantes hoy día para el Estado de Chile, parte en ellos, referidos a los Derechos Humanos, y a su protección, todos ellos, para los efectos de su aplicación, se remiten al derecho interno. En efecto:

1. Del Derecho Internacional Humanitario: los convenios de Ginebra, y específicamente el artículo $3^{\circ}$ común, que es el único que se refiere a la "guerra no internacional", dentro del territorio de un Estado. Junto con enumerar los hechos o acciones que configurarían ilícitos, en un conflicto armado interno, se remite a la ley interna para su aplicación concreta. Al efecto señala en su último inciso, ya indicado, que: "la aplicación de las anteriores disposiciones no surtirá efectos sobre el estatuto jurídico de las partes en conflicto". Y el Protocolo II, que lo complementa y desarrolla, insta a las autoridades en el poder a otorgar las más amplias amnistías posibles. 
2. Pacto Internacional de Derechos Civiles y Políticos. Es un tratado vinculante para el Estado de Chile, que es parte en él, desde 1989, y que concreta los propósitos y principios de la Declaración Universal de Derechos Humanos. Expresamente, $\left(\operatorname{art} .2^{\circ} \mathrm{n}^{\circ} 2\right)$, remite "a los procedimientos constitucionales [del Estado] "para dictar las medidas legislativas o de otro carácter, que fueren necesarias para hacer efectivos los derechos reconocidos por el Pacto y que no estuvieren ya garantizados por disposiciones legislativas o de otro carácter". Y tanto en el Pacto, como en la ley penal chilena están consagrados normas y principios jurídicos esenciales del derecho penal: principios de legalidad, reserva, tipicidad, pro reo, ne bis in idem, y, por ende, prescripción, y expresamente, derecho a la amnistía.

3. Convención Interamericana de Derechos Humanos. Es un tratado vinculante para el Estado de Chile, que es parte de él, y que reconoció la competencia de la Corte, sólo a partir de Agosto de 1990, y sólo para hechos cuyo principio de ejecución fuese anterior al 11 de marzo de 1990. La convención reitera, en general, la remisión al derecho interno del Estado la aplicación de los derechos y libertades que ella contempla. (art. $2^{\circ}$ ). Y, asimismo, reconoce los mismos principios jurídicos esenciales del derecho penal, recién indicados, y los beneficios procesales y penales de toda persona en la sustentación de cualquier acusación formulada contra ella. (arts. $4^{\circ} \mathrm{n}^{\circ} 6 ; 8^{\circ} \mathrm{n}^{\circ} 1$; y $9^{\circ}$ ). Lo que incluye los beneficios de la prescripción y de la amnistía.

Conclusión ineludible: la interpretación de los tratados indicados debe, necesariamente, ser efectuado de buena fe; y, también, acorde a la primacía del texto. Y no es jurídicamente consistente con las disposiciones indicadas de aquellos tratados que los tribunales del Estado y el tribunal internacional rehúsen aplicarlas en sus fallos, con el argumento de que no son aplicables, al aplicar los respectivos tratados. 
Esta paradoja tan extraña justifica por sí sola esta advertencia acerca de la grave pérdida de juridicidad que sufre el Derecho Internacional y el estado de derecho interno.

Tal vez la "UK Human Rights Act" lo ha sintetizado mejor en una sola disposición: "Los tribunales carecen de facultades para anular una ley (o decir que carece de efectos jurídicos) cuando la estiman incompatible con su interpretación (subjetiva) sobre derechos humanos". 